Original Article

\title{
Antidepressant Drug Effect on Periodontal Status in Chronic Periodontitis Patients
}

\author{
Shiny Inasu ${ }^{1}$, Biju Thomas ${ }^{2}$, Satheesh Rao ${ }^{3}$ Amitha Ramesh ${ }^{4} \&$ Smitha Shetty ${ }^{5}$ \\ Post graduate ${ }^{1}$, Professors ${ }^{2}{ }^{4}$, Senior Lecturer ${ }^{5}$ Department of Periodontics, A.B. Shetty Memorial Institute of Dental \\ Sciences, Nitte University, Mangalore. \\ Professor ${ }^{3}$, Department of Psychiatry, K.S. Hegde M edical Academy, M angalore - 575 018, Karnataka. \\ *Corresponding Author : Shiny Inasu, Department of Periodontics, A.B. Shetty Memorial Institute Of Dental Sciences, Nitte University, \\ M angalore, Karnataka-575018, India. Mobile : +919986672589 E-mail : shinyimd@gmail.com
}

$\begin{array}{ll}\text { Received } & : \text { 20-11-2015 } \\ \text { Review Completed } & : \text { 01-03-2016 } \\ \text { Accepted } & : 16-04-2016\end{array}$

Keywords : Antidepressant drugs, chronic periodontitis patients, periodontal status, psychiatric diseases.

\begin{tabular}{|c|}
\hline Access this article online \\
\hline Quick Response Code \\
\hline
\end{tabular}

\begin{abstract}
:
Patients with problems related to central nervous system dysfunctions are often treated with psychotropic drugs. These include antipsychotics, antidepressants, mood stabilizers, anticonvulsants, and drugs blocking specific receptors in the brain such as anticholinergics or beta-blockers. However, these medications have serious side effects affecting the oral health. The purpose of this study is to explore antidepressant drug effect in chronic periodontitis patients.
\end{abstract}

Aim : To explore the effect of antidepressant drug in chronic periodontitis patients.

Material and Methods : The study comprised of 100 subjects, 50 periodontally healthy subjects, 50 chronic periodontitis subjects .Clinical examination was done and the following parameters were assessed: Gingival index, Clinical Attachment Loss.

\section{Introduction}

Depression is a psychiatric disorder in which negative affect, depressed mood, disturbed thoughts, and altered behaviors persist for a minimum of two week. ${ }^{1}$ Antidepressants are prescribed for diverse therapeutic reasons including a variety of psychiatric disorders, pain control, insomnia, substance abuse and eating disorders.

Oral reactions to medications are common and affect patient's quality of life. Almost all classes of drugs, particularly those used continuously, such as antidepressants, may cause oral alterations. If not suitably treated, these may aggravate the patient's general state of health and affect his/ her oral health . ${ }^{1}$

A large number of medications used for the treatment of psychiatric diseases, have the side effects of dry mouth, diminished salivary flow speed and/or alteration in saliva composition ${ }^{3}$.The abusive use of drugs, mainly by elderly patients, may generate oral side effects (Lamy, 1984; Ciancio, 2004; ADA, 2005).

Persons with depression are also at high risk of developing periodontal disease, because neglected oral hygiene, increased smoking and altered immune response, associated with xerostomia facilitate increased colonization by pathologic bacteria in the mouth, leading to collapse of the periodontium (M oss et al., 1996; Elter et al., 1999).

Patients that receive atypical antidepressants may sometimes develop movement disorders that include bruxism or tooth-grinding, which may aggravate the patient's periodontal status (Brow \& Hong, 1999). 
Periodontitis is a chronic inflammatory disorder that gives rise to tissue damage and loss, as a result of the complex interaction between pathogenic bacteria and host's immune response.

\section{Objectives of the Study}

To evaluate the oral hygiene status among the subjects who are medicated under antidepressant drug.

\section{Material and Methods}

\section{Source of Data}

150 subjects who are medicated on antidepressant drug was selected from the Department of Psychiatry, K.S Hegde Hospital,and A.B. Shetty Memorial Institute of Dental Sciences, Deralakatte, Mangalore. Written informed consent was taken from all the participants before start of the study and was divided into two groups.

* Group 1-75 subjects who are medicated on antidepressant drugs for less than 6 months.

* Group II-75 subjects who are medicated on antidepressant drugs more than 6 months.

\section{Screening Examination Included}

- Medical history and Dental history.

- Whole mouth clinical periodontal measurements will be recorded.

- Gingival index [Loe and Silness 1963] to measure gingival status is doneclinical attachment levels will be determined with a UNC-15 probe.

\section{Criteria for Selection}

\section{Inclusion Criteria}

- Subject with a minimum complement of 20 teeth.

- Patients who are medicated on antidepressant drug (3-9 months).

\section{Exclusion Criteria}

Patients who have undergone any periodontal treatment in the last 6 months.

Pregnant women or lactating women.

Patients who are on antidepressant drugs less than 3 months.

\section{Statistical analysis}

Comparison of the two groups was done using independent t test.

Results

FREQUENCY TABLES

\begin{tabular}{|c|c|c|}
\hline 1) Have you visited dentist earlier? & \multicolumn{2}{|c|}{ Percent } \\
\hline YES & 102 & 68 \\
\hline NO & 48 & 32 \\
\hline Total & 150 & 100 \\
\hline
\end{tabular}

2) How often do you visit dentist?

\begin{tabular}{|l|c|c|}
\hline ONCE IN 3 M ONTHS & 34 & 22.7 \\
\hline ONCE IN 6 M ONTHS & 35 & 23.3 \\
\hline ONCE A YEAR & 33 & 22 \\
\hline ONLY IF NEED ARISES & 48 & 32 \\
\hline Total & 150 & 100 \\
\hline
\end{tabular}

3) Reason for visiting dentist

\begin{tabular}{|l|c|c|}
\hline General Check up & 20 & 13.3 \\
\hline Stains and deposits on the teeth & 37 & 24.7 \\
\hline Bleeding gums & 36 & 24 \\
\hline Pain & 57 & 38 \\
\hline Total & 150 & 100 \\
\hline
\end{tabular}

do you clean your teeth

\begin{tabular}{|c|c|c|}
\hline YES & 101 & 67.3 \\
\hline NO & 49 & 32.7 \\
\hline Total & 150 & 100 \\
\hline
\end{tabular}

5)how do you clean your teeth

\begin{tabular}{|l|c|c|}
\hline neem stick & 38 & 25.3 \\
\hline charcoal & 35 & 23.3 \\
\hline finger and tooth powder & 46 & 30.7 \\
\hline toothbrush and paste & 31 & 20.7 \\
\hline Total & 150 & 100 \\
\hline 7)
\end{tabular}

7)Ideal technique of brushing

\begin{tabular}{|l|c|c|}
\hline HORIZONTAL & 94 & 62.7 \\
\hline VERTICAL & 31 & 20.7 \\
\hline CIRCULAR & 6 & 4 \\
\hline BOTH A AND B & 19 & 12.7 \\
\hline Total & 150 & 100 \\
\hline B
\end{tabular}

8) Have you experienced bleeding while brushing?

\begin{tabular}{|c|c|c|}
\hline YES & 78 & 52 \\
\hline NO & 72 & 48 \\
\hline Total & 150 & 100 \\
\hline 9)If yes, what have you done for bleeding gums? \\
\hline CONSULTED DENTIST & 53 & 35.3 \\
\hline NOT VISITED DENTIST & 59 & 39.3 \\
\hline SELF M EDICATION & 38 & 25.3 \\
\hline Total & 150 & 100 \\
\hline 10)Do you think oral health can effect general health \\
\hline YES & 50 & 33.3 \\
\hline NO & 100 & 66.7 \\
\hline Total & 150 & 100 \\
\hline
\end{tabular}


11)Have you got oral prophylaxis (teeth cleaning )done

\begin{tabular}{|c|c|c|}
\hline YES & 43 & 28.7 \\
\hline NO & 107 & 71.3 \\
\hline Total & 150 & 100 \\
\hline 12 From wheredo you obtain your information
\end{tabular}

12)From where do you obtain your information on oral hygiene practices

FROM THE DOCTOR/DENTIST

\begin{tabular}{|l|c|c|}
\hline FROM MASS M EDIA & 42 & 28 \\
\hline FROM SCHOOL/COLLEGE & 99 & 66 \\
\hline Total & 9 & 6 \\
\hline
\end{tabular}

\begin{tabular}{|l|c|c|}
\hline 13)Do you smoke & \multicolumn{2}{l|}{} \\
\hline YES & 94 & 62.7 \\
\hline NO & 56 & 37.3 \\
\hline Total & 150 & 100 \\
\hline
\end{tabular}

\begin{tabular}{|l|c|c|}
\hline 14) If yes, how often? & \multicolumn{2}{l|}{} \\
\hline CURRENT SM OKER & 59 & 39.3 \\
\hline FORM ER SM OKER & 36 & 24 \\
\hline NON SM OKER & 55 & 36.7 \\
\hline Total & 150 & 100 \\
\hline
\end{tabular}

15)Are you aware of the deleterious effects of smoking on gum problems

\begin{tabular}{|l|c|c|}
\hline YES & 65 & 43.3 \\
\hline NO & 85 & 56.7 \\
\hline Total & 150 & 100 \\
\hline
\end{tabular}

\begin{tabular}{|l|c|c|}
\hline 16)Do you chew pan & \multicolumn{3}{l|}{} \\
\hline YES & 75 & 50 \\
\hline NO & 75 & 50 \\
\hline Total & 150 & 100 \\
\hline
\end{tabular}

17)Are you aware of the deleterious effects of pan chewing on gums

\begin{tabular}{|l|c|c|}
\hline YES & 37 & 24.7 \\
\hline NO & 113 & 75.3 \\
\hline Total & 150 & 100 \\
\hline
\end{tabular}

18)Are you on any drug therapy

\begin{tabular}{|l|c|c|}
\hline YES & 113 & 75.3 \\
\hline NO & 37 & 24.7 \\
\hline Total & 150 & 100 \\
\hline
\end{tabular}

\begin{tabular}{|l|c|c|}
\hline 19)If SO, which drug & 150 & 100 \\
\hline ANTIDEPRESSANT & 111 & 74 \\
\hline ANTIHYPERTENSIVE & 12 & 8 \\
\hline ANTIPSYCHOTIC & 13 & 8.7 \\
\hline ANY OTHER & 14 & 9.3 \\
\hline Total & 150 & 100 \\
\hline
\end{tabular}

\section{Discussion}

The results from above states that subjects who are medicated with antidepressant drugs for more than 6 months showed poor oral hygiene compared to those who were medicated for less than 6 months, using two clinical parameters: gingival index and clinical attachment loss. This may be due to neglected oral hygiene, increased smoking and altered immune response. Oral diseases in psychiatric patients are usually a result of bad oral hygiene and psychopharmaceutical side-effects. ${ }^{14}$

A study conducted by David Halpern et al, stated that 37\% of adults experience mood disorders at some point of time in their lives and by receiving many treatments and medications it undergoes adverse dental side effects, medications which are prescribed for mood disorder can cause dry mouth and increased rate of dental caries and periodontal disease especially in patients who are prescribed under antidepressant drugs. A depressed patient frequently has little interest or energy for even basic self-care activities ${ }^{12}$. Decreased energy and motivation, as well as negative self-views associated with depression may have a detrimental effect on oral hygiene habits and compliance with treatment recommendations ${ }^{11}$.

Subjects who are under medication still continue their habits like paan chewing, smoking and are unaware of the deleterious effects on gums as shown in the above results. Based on many population studies conducted among pan chewing and smoking patients, extrinsic staining of teeth due to paan and tobacco deposits is often observed particularly when good oral hygiene prophylaxis is lacking and where regular dental care is minimal. ${ }^{8}$ Subjects may chew paan to help deal with stress and boredom. Dealing with stress in other ways can help to reduce paan chewing. Some may chew paan to relieve tooth and gum pain. It is important to see dentist for proper dental treatment. ${ }^{8}$

Due to the improper brushing, maintaining oral hygiene, brushing technique and other habits changes healthy gingiva into gingivitis and later to chronic periodontitis causes poor oral status resulting in xerostomia and halitosis due to continuous use of antidepressant drugs. A study was conducted to examine the side effects in mouth due to antidepressant drugs which concluded that xerostomia is the main oral side effect associated with the various classes of drugs, particularly those used continuously. ${ }^{1}$ The daily use of multiple medications to treat chronic diseases and conditions is common among older adult. A recent study found that $40 \%$ of Medicare beneficiaries reported taking 
five or more prescription medications. These medicines can lead to an increased risk of serious adverse drug events, including a variety of oral problems. For example, mouth dryness. ${ }^{13}$

Subjects are unaware of the fact that oral health can affect the general health as mentioned in above results. Hence they should be advised, create a routine checkup and treatment should be provided and create awareness among themselves and others to improve their oral health as well as general health. Oral health affects people physically and psychologically and influences them, as well as their feelings of social well-being. ${ }^{4} \mathrm{M}$ any of the quality of life indicators in dentistry have focused primarily on older age groups, partly on the assumption that they would have had a lifetime's experience of oral ill health and thus are likely to perceive oral health as having a greater impact on their quality of life. ${ }^{15}$

Family members, however, must also be involved during the development of the preventative dental regime; if the depression does not adequately respond to therapy, the patient may lack the motivation and concentration necessary to autonomously comply ${ }^{13}$.

Instructions should be given in proper tooth brushing and flossing methods that maximize dental plaque removal. Artificial salivary products, antiseptic mouthwash (eg, chlorhexidine), and a $0.05 \%$ sodium fluoride, mouth rinse may be prescribed for patients with xerostomia. Dental treatment should consist of subgingival scaling, root planing and curettage, caries control, application of fluoride gel, and dental restorations. It is dentists' role as regards patients that make use of medications, to keep a detailed and updated medical history of their patients, in order to be alert to problems related to medication, and the impact of this on the diagnosis and treatment plan. ${ }^{1}$

It should be recognized that dentistry, in concert with medicine, has much to offer patients who are suffering under mental depression.

\section{Conclusion}

Antidepressants are medications prescribed to patients of all ages, for the treatment of a variety of psychiatric diseases (depression, affective disease, insomnia, anxiety, the panic syndrome and bipolar disorder) and is associated with a number of significant oral reactions. These complications, including xerostomia, sialoadenitis, gingivitis, dysgeusia, glossitis, tongue edema and discoloration and stomatitis, almost always appear due to dysfunction of the salivary gland induced by the medication.

Xerostomia is the main oral side effect associated with the various classes of drugs, particularly those used continuously. This symptom may be the result of both diminished salivary secretion and an alteration in saliva composition which can affect patient's emotional wellbeing, aggravate his/ her general state of health, as well as affect his/ her oral health. In order to determine whether or not the patient presents hyposalivation, the dentist can have a complementary exam, called sialometry, may be performed. If there is any doubt about the composition of the saliva, there are biochemical tests that can reveal alteration in its composition.

Communication between the doctor and dentist is extremely important, so that together, they re-establish the patient's general and oral health as far as possible.

\section{Independent T Test Used Here With}

\begin{tabular}{|l|c|c|c|c|c|c|c|}
\hline & GROUP & $\mathrm{N}$ & M ean & Std. Deviation & $\mathrm{t}$ & df & P VALUE \\
\hline \multirow{3}{*}{ Gingival index } & GROUP 1 & 75 & $\mathbf{0 . 9 5 1 1}$ & 0.48851 & - & & \\
\cline { 2 - 9 } & GROUP 2 & 75 & $\mathbf{2 . 7 4 0 5}$ & 0.33376 & 26.19 & 130.73 & $\mathbf{8 . 0 0 1}$ \\
\hline Clinical attachment losS & GROUP 1 & 75 & $\mathbf{4 . 4 0 6 1 3 3}$ & 28.04326 & - & & \\
\cline { 2 - 9 } & GROUP 2 & 75 & $\mathbf{7 . 2 3 9 2}$ & 1.263503 & 0.874 & 148 & 0.384 \\
\hline
\end{tabular}

The comparison of the two groups indicates that there is higher values in group 2 compared to group 1 in case of gingival index (Loeand Sillness 1985 ) and clinical attachment loss. 


\section{Gingival Index}

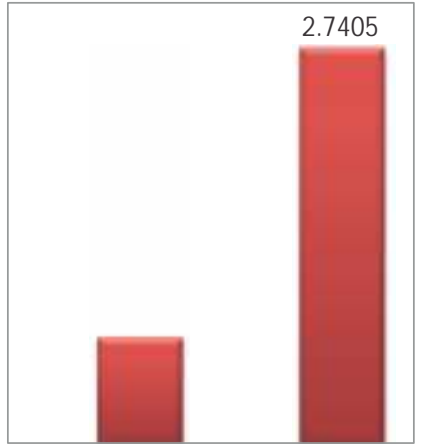

GROUP I

GROUP II
From the above results, a bar chart was plotted in which group2 (subjects who are under antidepressant medication more than 6 months)show higher value compared to group 1 (subjects who are under antidepressant medication for less than 6 months) solely for the purpose of assess the severity of gingivitis .Gingivitis is inflammation of the gingiva that does not result in clinical attachment loss, which is reversible and is often caused by inadequate oral hygiene.

\section{Clinical Attachment Loss}

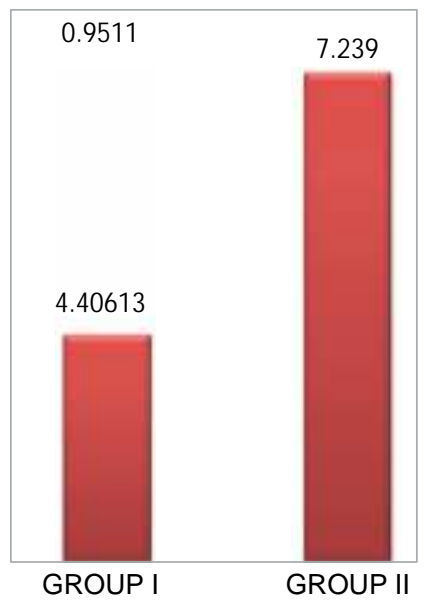

From the above results, a bar chart was plotted in which group2 (subjects who are under antidepressant medication more than 6 months)show higher value compared to group 1 (subjects who are under antidepressant medication for less than 6 months), represents the disease severity in terms of

\section{2) How often do you visit dentist?}

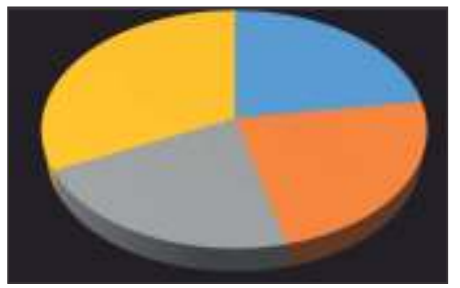

Once in 3 Months

$\square$ Once in 6 Months

$\square$ Once a Year

$\square$ Only if Need Arises

\section{3) Reason for visiting dentist?}

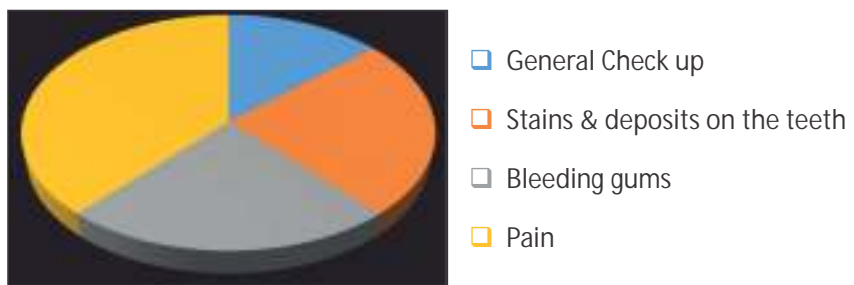

4) Do you clean your teeth?

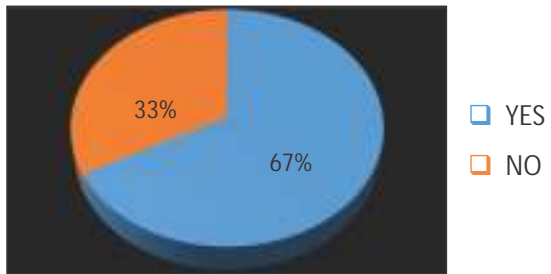

\section{5) How do you clean your teeth?}

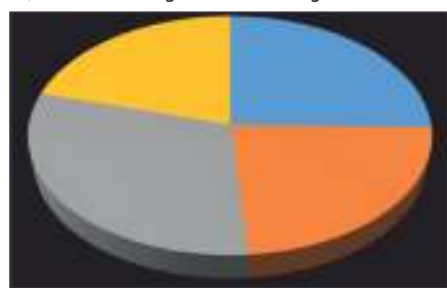

neem stick

$\square$ charcoal

$\square$ finger and tooth powder

$\square$ toothbrush and paste

\section{6) Do you clean your teeth regularly?}

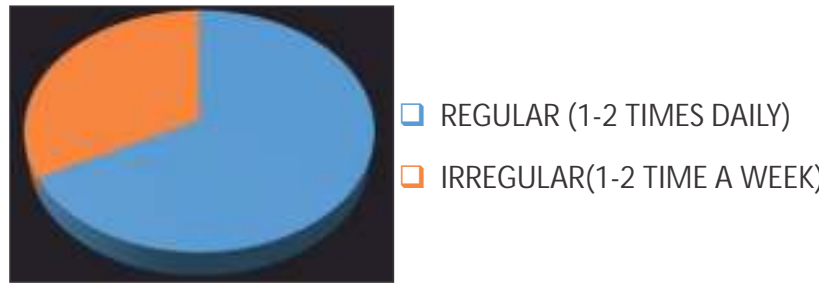

\section{7) Ideal technique of brushing}

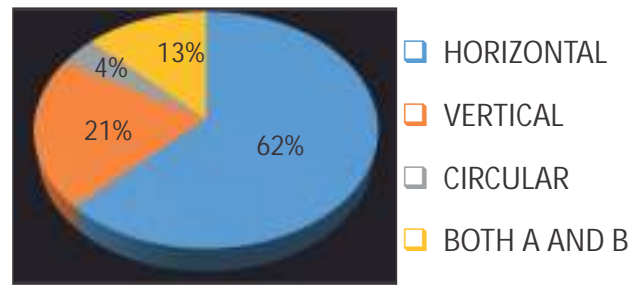


8) Have you experienced bleeding while brushing?

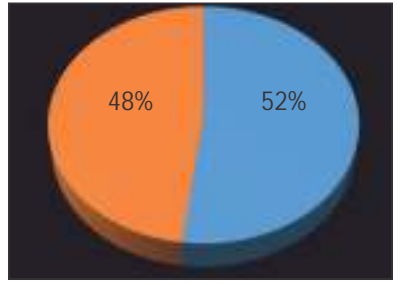

$\square$ YES

$\square \mathrm{NO}$

9) If yes, what have you done for bleeding gums?

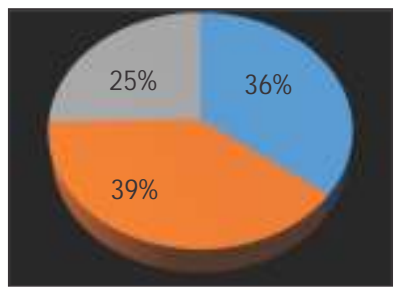

$\square$ CONSULTED DENTIST

$\square$ NOT VISITED DENTIST

$\square$ SELF MEDICATION

10) Do you think oral health can effect general health?

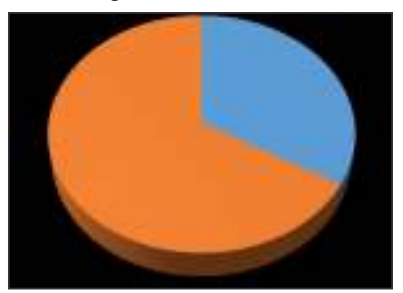

$\square$ YES

$\square$ NO

11) Have you got oral prophylaxis (teeth cleaning) done?

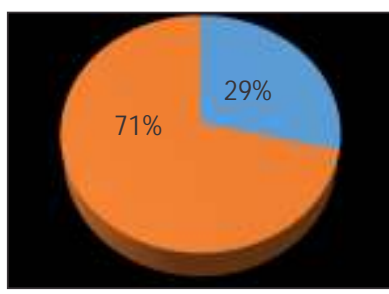

$\square$ YES

$\square$ NO

12) From where do you obtain your information on oral hygiene practices?

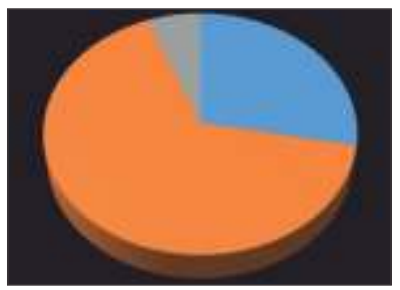

$\square$ FROM THE DOCTOR/DENTIST

$\square$ FROM MASS MEDIA

$\square$ FROM SCHOOL/COLLEGE

13) Do you smoke?

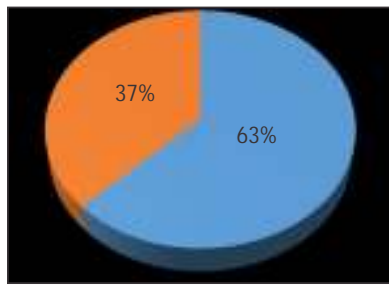

$\square$ YES

$\square$ NO
14) Ifyes, how often?

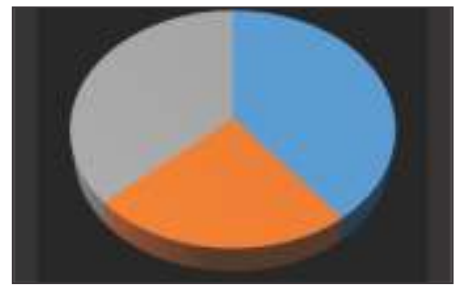

$\square$ CURRENT SM OKER

$\square$ FORM ER SM OKER

$\square$ NON SM OKER

15) Are you aware of the deleterious effects of smoking on gum problems?

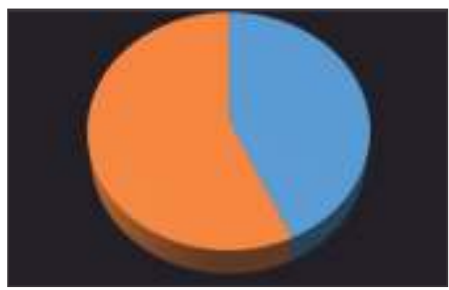

$\square$ YES

$\square$ NO

16) Do you chew pan?

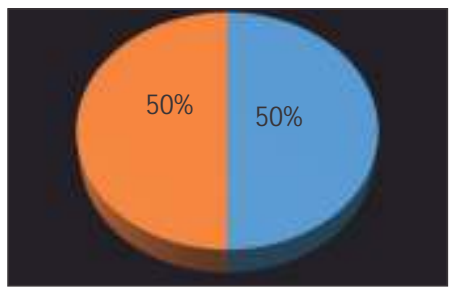

$\square$ YES

$\square$ NO

17) Ifyes, how long?

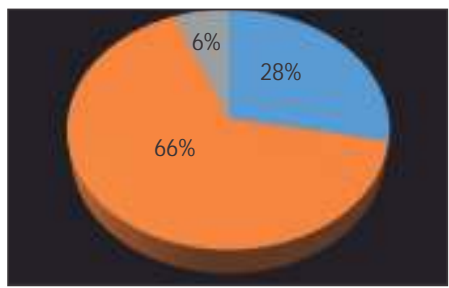

$\square$ more than 6 years

$\square$ More than 12 years

$\square$ less than 6 years

18) Are you aware of the deleterious effects of pan chewing on gums?

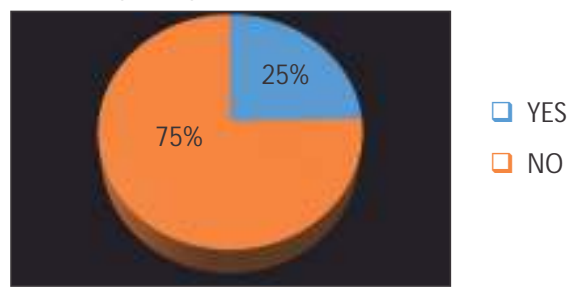

19) Are you medicated on any drug?

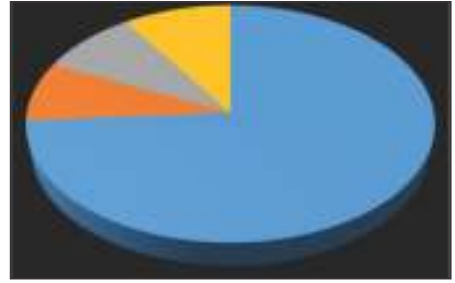

ANTIDEPRESSANT

$\square$ ANTIHYPERTENSIVE

$\square$ ANTIPSYCHOTIC

$\square$ ANY OTHERS 


\section{References}

1. Lamy, M . (1984). Drugs and oral health. Journal of the Maryland State Dental Association, Vol.27, No.3, (December 1984), pp.125-130, ISSN 0025-4355.

2. American Dental Association [ADA] - Division of Communications (2005). for the dental patient. How medications can affect your ora health. Journal of the American Dental Association, Vol.136, No.6, (June 2005), pp.831, ISSN 0002-8177

3. Smith, R. \&Burtner, A. (1994). Oral side-effects of the most frequently prescribed drugs. Special care in dentistry, Vol.14, No.3, (May-June 1994), pp.96-102, ISSN 0275-1879.

4. Locker D. Concepts of oral health, disease and the quality of life. In: Slade GD, editor. M easuring oral health and quality of life. Chapel Hill: University of North Carolina, Dental Ecology; 1997, pp. 11-23.

5. Sreebny, L. \& Schwartz, S. (1997). A reference guide to drugs and dry mouth: 2nd edition. Gerodontology, Vol.14, No.1, (July 1997), pp.3347, ISSN 0734-0664

6. Bardow, A.; Nyvad, B. \&Nauntofte, B. (2001). Relationships between medication intake, complaints of dry mouth, salivary flow rate and composition, and the rate of tooth demineralization in situ. Archives of oral biology, Vol. 46, No.5, (M ay 2001), pp.413-423, ISSN 0003-9969.

7. Brow, E. \& Hong, S. (1999). Antidepressant-induced bruxism successfully treated with gabapentin. Journal of the American Dental Association, Vol.130, No.10, (October1999), pp.1467-1469, ISSN 0002-8177.

8. TrivedyC,Warnakulasuriya $S$, Peters $T$ J. Arecanuts chewing have deleterious effects. Br M edJ 1999; 318:1287

9. Von Knorring, A. \&Wahlin, Y. (1986). Tricyclic antidepressants and dental caries in children. Neuropsychobiology, Vol.15, No.3-4, (1986), pp.143-145, ISSN 0302-282X.

10. Friedlander, A. \& Mahler, M. (2001). Major depressive disorder: psychopathology, medical management and dental implications. Journal of the American Dental Association,Vol.132, No.5, (M ay 2001), pp.629-638, ISSN 0002-8177

11. Elter JR, White BA, Gaynes BN, Bader JD. Relationship of clinical depression to periodontal treatment outcome. J Periodontol 2002 Apr; 73(4):4419.

12. Friedlander AH, Mahler ME.Major depressive disorder. Psychopathology, medical management and dental implications. J Am Dent Assoc 2001M ay; 132(5):629-38.

13. Douglas B. Berkey and Frank A. Scannapieco.M edical considerations relating to the oral health of older adults. Special Care in Dentistry, Volume 33, Issue 4, pages 164-176, July/August 2013.

14. M aes M 1, Berk M, Goehler L, Song C, Anderson G, Galecki P, Leonard B. Depression and sickness behavior are Janus-faced responses to shared inflammatory pathways. BM CM ed. 2012 Jun 29; 10:66.

15. SudhanshuSanadhya, PankajAapaliya, Sorabh Jain, Nidhi Sharma, Garima Choudhary, and NiraliDobaria. Assessment and comparison of clinical dental status and its impact on oral health-related quality of life among rural and urban adults of Udaipur, India: A cross-sectiona study.J Basic Clin Pharm. M arch 2015-M ay 2015; 6(2): 50-58. 